\title{
Motorola Cash Management: The Evolution of a Global System
}

\author{
Christopher Holland \\ Information Technology Institute \\ University of Salford \\ Salford \\ M5 4WT
}

\author{
Jean-Michel Richard \\ Motorola Limited \\ European Treasury
}

\author{
Geoff Lockett \\ Manchester Business School \\ University of Manchester \\ Manchester \\ M15 6PB
}

\author{
Ian Blackman \\ Citibank \\ Cash Management
}

\begin{abstract}
Organisations are implementing joint information systems with suppliers, customers and banks. The generic name for these systems is Inter-Organisational Information Systems (IOSs). In this paper the set of IOSs used for global cash management in business markets is analyzed. A longitudinal case study of Motorola is presented. Their strategy has evolved from an internal cost saving focus to a cooperative one yielding significant strategic benefits by the inclusion of trading partners. The financial aspects of Motorola's business relationships with trading partners and its principal bank has been transformed through a process of organisational learning and adaptation coupled with the close integration of Information Systems throughout the cash supply chain. Cooperative behaviour between Motorola and its suppliers, with the help of Citibank, has enabled a coordinated response to bring cash flows in line with product flows. The results are compared with existing IS/marketing theories on business relationships, market structure and globalisation. It is shown that Motorola is developing hierarchical links with its suppliers rather than developing an electronic market.
\end{abstract}

\section{Introduction}

Globalisation of competition has been identified as a general trend and new types of organisations are emerging to service global markets (Porter,1990). Manufacturing, distribution and marketing strategies are being coordinated on a global scale. Information Systems are a key part of globalisation strategies because computer networks enable large volumes of data to be moved across great distances almost instantaneously therefore negating the importance of geographic dispersion (Manheim, 1992). Data and applications can therefore be shared easily and quickly between managers on different continents.

European manufacturing and sales data can be collated with data from Japan with little difficulty. Similarly a mainframe computer which is physically in the United States may be accessed by a manager using a terminal in Europe. These trends present new opportunities for management to re-design their organisations and also their relationships with trading partners. In this paper the changing role of treasury management in Motorola is traced over a period of sixteen years. Organisational, strategic and Information Technology shifts are presented. In the context of trends in manufacturing and marketing such as increased integration between organisations and just-in-time product flows (Freeland and Ashby, 1987), cash management is an important business process because of the potential benefits and inevitable outcome of cash flows moving so as to be in line with product flows.

\section{Problem Statement}

Motorola manufacture and market a wide range of electronic products throughout the world. Separate Motorola companies act autonomously and therefore trade with each other, often across national boundaries. An internal Information Systems infrastructure which enables data to be shared easily between Motorola companies has been in place since 1976. It is used in logistics and manufacturing management to reduce costs and improve the quality of manufacturing operations in a continuous improvement programme. In parallel with these developments, the treasury management function has evolved to manage nearly $\$ 5 \mathrm{bn}$. dollars of within company payments. An internal "currency netting" system has been developed and the treasury function reorganised. This has taken control from local management 
and centralised all foreign currency payments. Primarily used for Worldwide inter-Motorola company payments, Motorola's netting system is now also used as a vehicle to pay suppliers cross-border. The research problem can be formulated as a series of complementary questions:-

1. What are the coordination mechanisms to manage cash flows between Motorola companies and their suppliers? Is there a trend towards electronic hierarchies or electronic markets?

2. What is the role of Citibank, the principal banker to Motorola in the development of payment services?

3. Are there any generalisable trends in cash management and what are their managerial implications for manufacturers and banks?

In the next section the development of the whole system is outlined and its major phases described in more detail. The discussion of the IS literature is presented in a later section so that a detailed comparison can be made between this case and various theories.

\section{Cash Management Strategy}

The evolution of Motorola's cash management strategy has taken place over a period of sixteen years. During this time there have been major changes in Information Technology, strategic direction and focus while the system has been growing. The original objective was to improve cash management within the group using existing Motorola controlled computer networks. A currency netting system was applied to transactions between Motorola companies to achieve cost savings by both reducing cash flows and the amount of foreign exchange deals effected for international payments. This concept is now being extended to include suppliers and involves the extensive use of Value-Added-Networks (VANS) and cooperation with Citibank. The emphasis in the second phase is to improve the management of the financial aspects of supplier relationships as well as to increase the benefits of reduced cash flows and foreign exchange savings already achieved in the first phase. Strategy development is therefore described in two sections.

\subsection{Phase One - Internal Netting}

The concept of internal netting is described and illustrated with a model of four companies of different nationality. The full organisational, technical and geographic details of the system are presented in the external netting section.
Once every week all foreign currency transactions between Motorola companies are managed with a single payment or invoice from the centre to each Motorola company. National currencies are handled by the separate Motorola companies and are not part of the scheme. On Monday at $11.00 \mathrm{a} . \mathrm{m}$. data are collected from all netting users. This consists of a transaction file and vendor data. The netting system is then locked to achieve a clean cutoff point. On Tuesday p.m. the total accounts payables and receivables are known by the treasury management centre. Each company is then advised by electronic mail whether it will receive a payment or is required to pay the centre. All transactions are conducted in local currencies so a German company receives or makes a payment to the centre in Deutschmarks for all its foreign currency transactions. An illustrative example of currency flows is shown in figure one and a small numerical example is detailed in figure two.

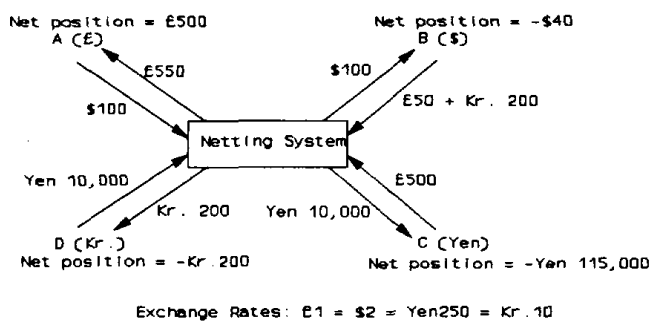

Figure 1. Schematic Model of Currency Netting

\begin{tabular}{|c|c|c|c|c|c|c|}
\hline \multirow[b]{2}{*}{ A ( } & $A(f)$ & \multirow{2}{*}{$\begin{array}{r}\mathrm{B}(\$) \\
\$ 100\end{array}$} & \multirow{2}{*}{$\begin{array}{c}C(\text { Yen }) \\
0\end{array}$} & \multicolumn{2}{|c|}{$\mathrm{D}(\mathbf{K r} \mathbf{r})$} & $\sum_{j=1}^{4} M_{x j}$ \\
\hline & 0 & & & 0 & ) & $£ 50$ \\
\hline B ( & $£ 50$ & 0 & 0 & Kr.200 & ) & $\$ 140$ \\
\hline C ( & $£ 500$ & 0 & 0 & 0 & ) & Y.115,000 \\
\hline D ( & 0 & 0 & Y . 10,000 & 0 & ) & $\mathrm{Kr} .400$ \\
\hline$\sum_{i=1}^{n} M_{i}$ & $E 550$ & $\$$ & Y.10, &, 000 & r. 2 & \\
\hline
\end{tabular}

Figure 2. A Payment Matrix $\left(M_{v}\right)$ Netting Model of Currency Transactions 
The net payments for each company are easily calculated:-

$$
\begin{aligned}
& \text { A }(£ 550-£ 50=£ 500) \\
& \text { B }(\$ 100-\$ 140=-\$ 40) \\
& \text { C }(Y .10,000-Y .125,000=-Y .115,000) \\
& \text { D }(\text { Kr. } 200-\text { Kr.400 }=-\mathrm{Kr} .200)
\end{aligned}
$$

The payments matrix $M_{i j}$ represents the accounts payables and receivables of four companies A, B, C and D. The columns represent the accounts receivables and the rows represent the accounts payables for each company. For example, company A needs to pay $\$ 100$ to company $B$ and will receive $£ 50$ and $£ 500$ from companies $B$ and $C$ respectively. The total account payables for each company can therefore be represented by the sum of its row. Similarly, the total account receivables for each company is represented by the sum of its column. In mathematical notation:-

For company $x$,

$\begin{array}{ll}\text { Sum of accounts payables }= & \sum_{j=1}^{4} \mathrm{M}_{\mathrm{xj}} \\ \text { Sum of accounts receivables }= & \sum_{\mathrm{i}=1}^{4} \mathrm{M}_{\mathrm{ix}}\end{array}$

Net position $=\underset{\mathrm{i}=1}{\stackrel{4}{5} \mathrm{M}_{\mathrm{ix}}}-\underset{j=1}{4} \mathrm{M}_{\mathrm{xj}}$

Before netting, the total amount of cash flows was the sum of all payments which in dollar value is $\$ 1,480$. The netted cash flows for each company is the sum of its payables less the sum of its receivables. Therefore, in local currencies, A will receive $£ 500$, B will pay $\$ 80$ dollars, C will pay $Y .4,000$ and D will pay $\mathrm{Kr} .300$. For ease of comparison, the netted cash flow in dollars is $\$ 1,000$. The centre receives three different types of currencies and makes one payment to company $A$ and it has a neutral cash position.

The benefits arising from this system are a reduction in cash flows and also of the amount of foreign exchange deals. By moving from localised treasury management operations to one centralised team of dedicated staff, it is estimated that an annual financial saving (bank charges, foreign exchange) of about US\$6.5M. is achieved. However this does not include administrative savings gained from streamlining the operations which obviously are more difficult to quantify. These have not been measured because the system is seen to be an outstanding success for the treasury management centre and all the companies. Each separate organisation has taken the benefits in reduced costs. It was made possible because of a combination of factors. The first one is the foresight of the senior management. They had already committed themselves to be at the forefront of I.T. and see its use as giving them strategic advantage. The basic network was therefore already in place and once the scheme had been proposed, its value was obvious to the participants organisational resistance was low. It was also gradually introduced by building on successful stages of implementation. A few sites were chosen as prototypes in the first instance. Once these systems had become established and any operational difficulties resolved the inclusion of other sites took place without difficulty.

\subsection{Phase Two - External Netting}

Once the internal cash management was working smoothly Motorola then turned its attention to customers and suppliers. By this time it felt it had developed the necessary expertise to attempt this more difficult task. However it is a far more complicated procedure in practice - not in concept - because of the involvement of a potentially large number of banks and their Information Systems. The way round this problem has been the cooperation with a complementary global banking company, Citibank, who had been considering the same problem. Their unique system of delivery fitted neatly with Motorola's system of collection - a clear example of synergy. The overall aim for Motorola was to fully automate their netting system and communication platform with Citibank. This is the logical parallel development with EDI for logistics operations.

The process for external netting and payments is presented in figure three which depicts the information flows and geographic locations. In essence the system is very simple. Each week every Motorola netting entity (factory) sends a transaction file detailing payments to suppliers and a vendor database to the clearing centre mainframe in Chicago. The treasury function in London controls the netting system from the mainframe, collects the data by closing system access, proceeds with the foreign exchange transactions, initiates payment orders and finally advises Motorola companies of their net position.

After netting incomings with outgoings and combining common currencies an approximate foreign exchange position is reached in which surplus currencies are sold and deficit currencies are bought. The transaction value is approximately US\$30M. per week. Two first tier banks and one from a pool of other banks are asked to quote for the foreign exchange dealings.

For external payments, better control is required because mistakes are more difficult and expensive to 


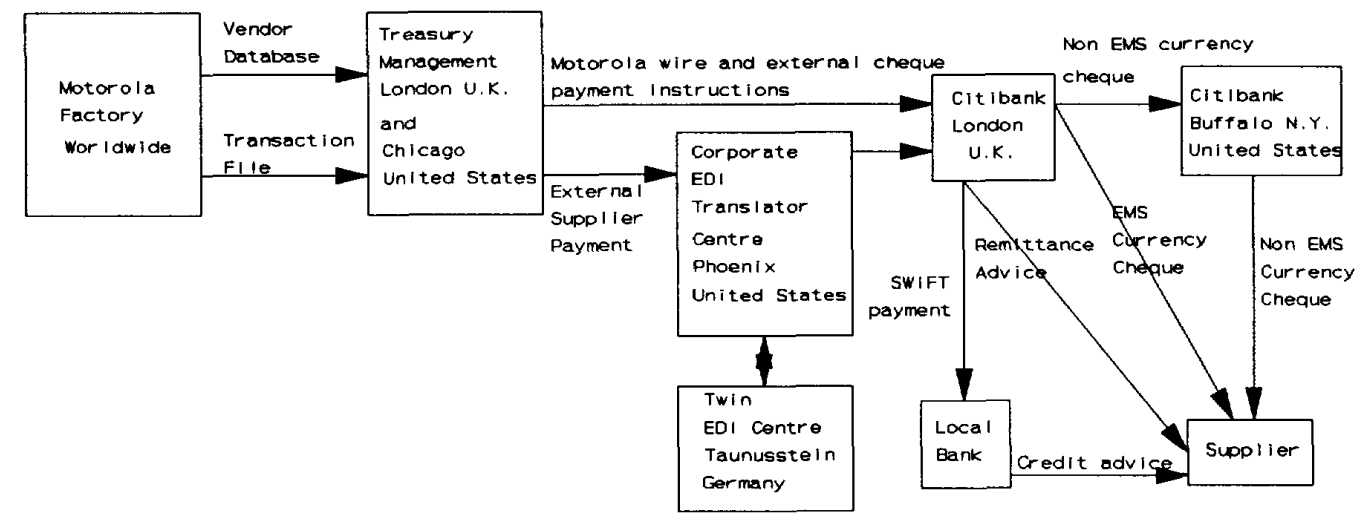

Figure 3. Organisational Information Flows for Global Payments System

rectify. Therefore, before payment instructions are sent to Citibank, a pre-notice message is sent to each Motorola entity which lists all payments to external suppliers (i.e. non-Motorola companies). The factory controller must give permission before the payments can proceed and can amend or delete payments. The cost of mistakes, principally unnecessary foreign exchange dealings, are borne by the individual netting entities. Therefore the central treasury function is in essence acting as an international bank.

There are three main classes of payment. These are:(1) Electronic Payments to Motorola companies.

(2) Cheque payments for less than $\$ 10,000$ in value to external suppliers.

(3) Electronic bank transfer payments over $\$ 10,000$ in value to external suppliers.

Payments to Motorola companies and cheque payments for less than $\$ 10,000$ are sent direct to Citibank London. Cheque payments are made through 'Worldlink', a PC based application developed by Citibank to generate cheques off-site. It is an interface for the automatic feed of netting systems payments to external suppliers into Citibank's cheque generation system in Buffalo, New York. If the cheque is payment for more than four invoices then the remittance advice is printed separately and sent with the cheque, each document referring to the other. Otherwise, remittance advice is printed directly onto the cheque. Payments to Motorola companies are all sent by bank transfers. (Motorola companies have already received pre-notice advice of payments on Tuesday p.m. before the Thursday value-date.)
External supplier payments are slightly more complex. Details of supplier payments and remittance advices are sent to the corporate EDI centre in Phoenix (Arizona) for translation into an EDIFACT format. This acts as an electronic gateway for all EDI messages from Motorola to its trading partners and vice-versa. The payments details and EDIFACT standard remittance advices (PAYEXT) are then transmitted to Citibank London. SWIFT standards are used to effect the payment through the international banking system and the remittance advice is sent separately and directly to the supplier using a predefined VAN. Suppliers wished to receive a direct remittance advice from Citibank which includes the value date of the payment rather than use the SWIFT network as a conduit for receiving this information.

Although beyond the remit of this paper this latter point needs more comment. At the moment most cross border payments are completely managed by the banks and the time for money to become available is highly variable. It may involve up to 6 or 7 banks and take between 14 and 20 days for the organisation receiving a payment to have the cash ready for use. Apart from the transaction costs (often hidden) the more important problem is that of cash management. In the system described the supplier is informed of the value date of the payment - the day of it going into the banking system and the day funds should be credited into the beneficiary's bank account. With modern electronic systems there is no reason why the cash should not be credited to the beneficiary's bank at the value date. This is allowing more than adequate time for checking and controlling systems to work effectively. Just-In-Time money should be possible and the system described is a major advance in that direction. 
The payments system uses a variety of different computer networks to support the sharing of data and software between Motorola companies, its trading partners, Citibank and other banks involved in the cash supply chain. Communication between Motorola companies and the central treasury management function is via an internal electronic mail system composed of three sub systems covering the Central, Mountain and Pacific area time zones. Motorola's treasury management function uses a dial-up line to access Citibank's Global Telecommunications Network. The corporate EDI centre is connected to Citibank London via a VAN which is also used to transmit remittance data to suppliers. Data security is ensured through the use of data encryption techniques and contingency/recovery plans are built into the system by mirroring all the activities of the Phoenix corporate EDI centre in Taunusstein, Germany. Citibank uses its own global network to transfer payment details between its branches and the Society for Worldwide International Funds Transfer (SWIFT) network to communicate with other banks to effect electronic bank transfer payments. A variety of different VANs are used to communicate the remittance advice between Citibank and Motorola's suppliers. These are chosen by the suppliers and include AT\&T, Istel's INS and IBM's IIN.

Initially most of the effort was internal to Motorola. However in many respects Motorola companies are mostly autonomous and they are very similar to both suppliers and customers. Therefore when the external connections were suggested and later attempted it was seen as a natural progression. Very few technical difficulties have been encountered and with 'good will' it appears to be a win-win situation. Cooperation need not be against competition.

\section{Evolution and Growth}

The success of the system is due to many factors and has some similarities with other large scale Information Systems which are used to gain competitive advantages (Clemons and Row, 1992a, Venkatraman and Short, 1992). It has been driven along by a clear vision - the electronic handling of money, and the associated simplifications that this brings. However in common with other large and successful systems it has evolved over a considerable period of time as detailed below.

Table one details the evolution of Motorola's cash management strategy starting with the implementation of an internal global electronic mail system to the inclusion of external suppliers into the netting system. The main systems implemented by Citibank on the Motorola project are shown in table two. It should be remembered that
Citibank has been developing global computing banking systems for a long period of time. Like Motorola their success in this field has given them confidence to continue major strategic developments in cash management payment systems. Both organisations take a global strategic stance. Table three shows the growth in cash flows between Motorola companies from 1983 to 1991.

The payments settled column is the sum of the accounts payables of all netting companies. The net cash flow in 1991 was $\$ 2,400 \mathrm{M}$. which is a reduction of almost $\$ 2,380 \mathrm{M}$. The foreign exchange with banks is the total value of currencies bought and sold. Without netting, it is expected that the figure for 1991 would have been $\$ 4.3 \mathrm{bn}$. which represents a reduction of $\$ 3 \mathrm{bn}$. worth of foreign exchange transactions which equates to a direct annual saving of approximately $\$ 6.5 \mathrm{M}$. on foreign transactions alone.

There are approximately 2,000 transactions per month. At the moment, only a small number of suppliers are receiving remittance advice electronically but it is planned to have the great majority of suppliers linked in this way in the next five years. Growth in the number of suppliers is expected to increase rapidly as the system gradually becomes seamless. Other improvements are to the Information Technology links between Motorola companies and the treasury function. Most of the data are entered manually at each factory. In these cases aggregate payment data only are recorded. Several of the leading edge users have direct interfaces to the centre which enables treasury management to pull transaction and vendor files directly off their systems. This improves the accuracy of the data and is less of an administrative load on the factories.

\section{Discussion}

A strong business vision coupled with the I.T. platforms of Motorola and Citibank have made it possible to implement a global cash management system which benefits both Motorola and its suppliers. This has been achieved through gradual innovations and is characterised by a learning process which allows the organisations to become accustomed to technical and organisational change and shift the strategy focus from an initial cost saving initiative to one that now yields significant strategic advantage. The Information Systems are being used to tie together the financial processes of Motorola companies and their suppliers by integrating the cash supply chain of Motorola, Citibank, suppliers' banks and suppliers. Although it looks complicated it is simply using EDI to its fullest extent. There are now no technical reasons why 

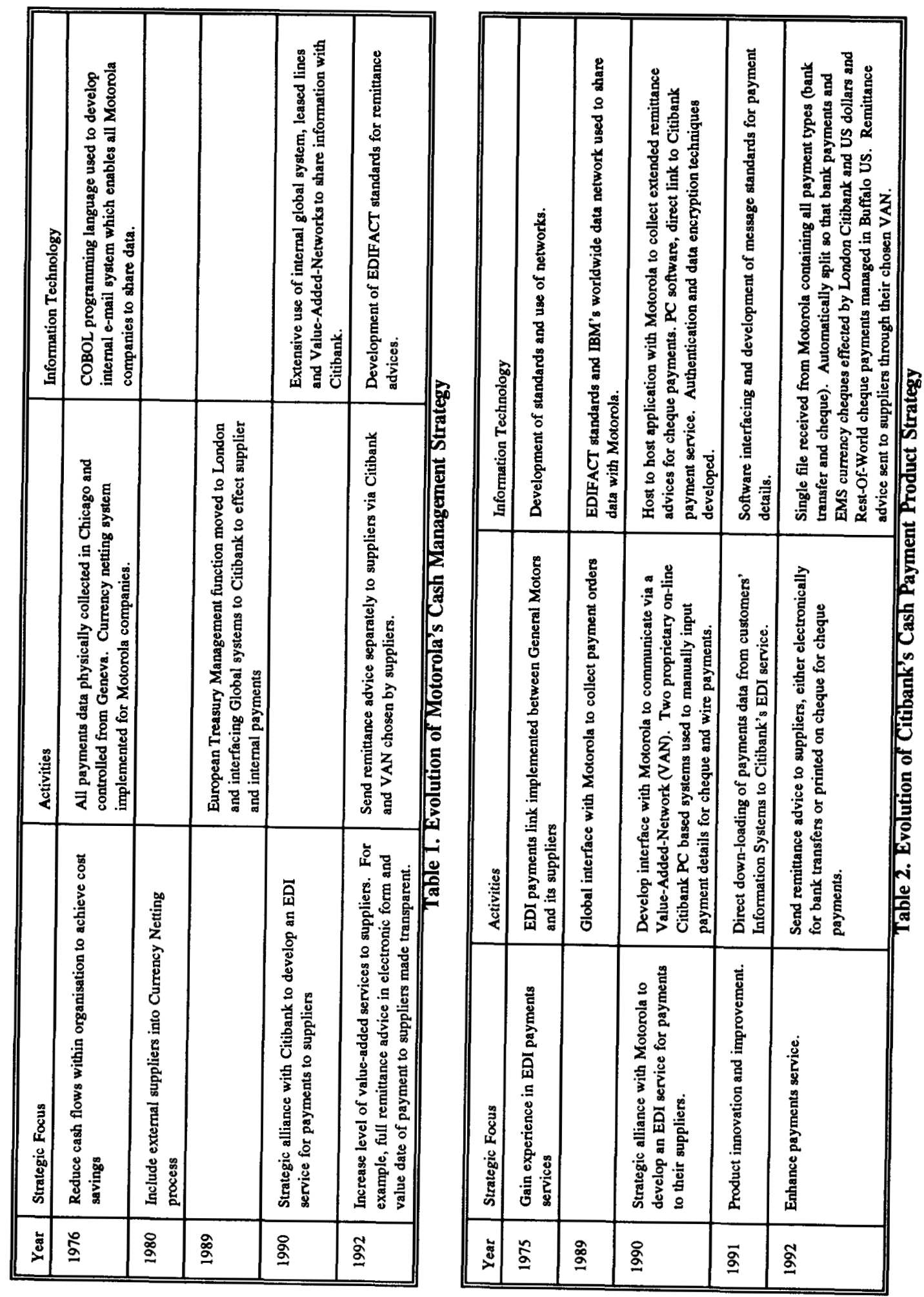

455 


\begin{tabular}{||l|l|l|l||}
\hline Year & $\begin{array}{l}\text { Payments Settled } \\
\text { (in \$M.) }\end{array}$ & $\begin{array}{l}\text { Foreign Exchange with } \\
\text { Banks (in \$M.) }\end{array}$ & $\begin{array}{l}\text { Number of Motorola } \\
\text { Participants }\end{array}$ \\
\hline 1983 & 600 & 229 & 38 \\
\hline 1984 & 800 & 361 & 51 \\
\hline 1985 & 1,100 & 391 & 53 \\
\hline 1986 & 1,300 & 432 & 57 \\
\hline 1987 & 1,800 & 415 & 65 \\
\hline 1988 & 2,700 & 510 & 76 \\
\hline 1989 & 3,000 & 650 & 85 \\
\hline 1990 & 3,391 & 1,100 & 103 \\
\hline 1991 & 4,780 & 1,281 & 106 \\
\hline
\end{tabular}

Table 3. Growth of Motorola's Cash Management Netting System

cross border payments should not be made quickly and to a specified time. Motorola's cross border payment system informs all companies on the Tuesday of each week as to what their exact cash position will be on the Thursday. This case represents a move towards Just-InTime money and may bring the banks into line with manufacturing organisations. An electronic revolution in banking may eventually occur.

The handling of Information Technology is no longer seen as a barrier to innovation and change in the cash management strategy. Both Motorola and Citibank have internal global networks which allow them to transfer data relatively easily between any sites. The system also has many additional advantages, e.g. it allows managers to use applications which are located physically in another country. For example, treasury management is currently based in London but it could be anywhere on the network. The treasury management function is effectively location independent. Europe has been chosen as a centre because of its time zone position, Motorola's strong manufacturing presence in Europe and accessibility to London's financial markets.

\section{Key Results}

The key results are concerned with cash supply chains, financial relationships in business markets and strategy evolution. It can be seen that cash flows are being brought into line with product flows. The coordinating mechanisms to achieve it centre around the transparency of information from the transaction file and vendor database of the payer through to the supplier. It has been achieved largely through cooperation between a global manufacturer, a global bank and suppliers to Motorola the payments systems described in this paper would be very difficult to implement with a group of national banks or with adversarial style supplier relationships. It depends critically on organisations which expect to work closely with each other, i.e. they have a strong basis for trust and share common needs.

Motorola's cash management strategy has evolved over a long period of time, has delivered significant cost savings and is now being exploited strategically in the enhancement of supplier relationships. The cost savings are direct financial ones associated with reduced foreign exchanged dealings worth approximately $\$ 6.5 \mathrm{M}$. and administrative savings associated with the streamlining of the treasury function which is perhaps worth considerably more but is difficult to measure accurately.

Cooperation between Motorola and Citibank has enabled a better payment system to be developed. It is therefore difficult to separate out individual firm strategies as Motorola and Citibank each benefit from the other's resources and expertise. This can be described as a cooperative strategy to streamline the cash supply chain from customer to supplier. Both organisations see themselves in global terms and provide worldwide services. They speak in a similar language.

Information Systems form the backbone of the cash management strategy but the problems being encountered now are organisational rather than technical. The technology is not presenting significant problems and the limiting factors on implementation are the ability of the 
organisation to learn and adapt to new treasury management ideas. Central to the implementation are resources for education and training for Motorola companies and their suppliers.

\section{Comparison with Theory}

The implementation of a global cash management system between Motorola and its trading partners has been viewed as an applied management/IS problem. A managerial perspective has been taken which means that relevant IS theories are fragmented across many different subject disciplines but in particular strategy and associated competitive advantage literature, marketing, economics and organisational behaviour. Given this complexity, the principal results are compared with management/IS theories connected with the themes of evolution of InterOrganisational Information Systems (IOSs) and the emerging forms of business relationships and market structures.

The potential of IOSs to enable a company to achieve competitive advantage is now well documented, e.g. Cash and Konsynski (1985), Johnston and Vitale (1988), Benjamin et al (1988), Rackoff et al (1985). However, there is considerable disagreement on the emerging forms of organisations, business relationships and market structures. There is also the problem of strategy choice for individual organisations. General IS theories on the impact of IT on organisations (e.g. Huber, 1990, Keen, 1990, Whisler, 1970, Zuboff, 1988, Bjorn-Andersen et al, 1986) all agree that organisational design and change are intimately related to the implementation of IT. For example, Bjorn-Andersen et al (1986) argue that the impact of IT on organisations is principally a process of organisational design by managers and that in general IT does not have a pre-determined influence other than to increase the transparency of information. This conclusion is significant because it highlights the role of managerial choice in IT implementation. A complementary view is given by Keen (1990) in an analysis of the application of telecommunications to assist organisational performance. Keen (1990) asserts that telecommunications remove the dichotomy of centralization and decentralization and 'centralization-with-decentralization' is therefore made possible. The organisational changes which have occurred in Motorola's treasury management function support the notions of managerial choice and centralization with decentralization. The treasury management function is evolving into a global, companywide standardised business process. It is these internal changes which have provided the impetus and confidence for the organisation to make further innovations with suppliers and customers.

At an inter-organisational level the areas of interest are business relationships and market structure rather than single organisations. Rockart and Short (1989) observed the abundance of theories but lack of consensus in this area and conceptualised the problem as one of managing organizational interdependence. This focuses attention on the potential benefits to be gained at an interorganisational level and is supported by case evidence and theoretical models reported by Johnston and Lawrence (1988) and Konsynski and McFarlan (1990) amongst others. A more extensive theory on the coordination mechanisms to control interactions between organisations is the theory of electronic markets which makes several predictions (Malone et al, 1987, Malone et al, 1989). In this scenario multiple buyers and multiple sellers have equal and open access to all market data and are therefore able to search and evaluate competing product offerings of suppliers or competitors facilitated by the use of IOSs for sharing data. An important prediction is that organisations will not achieve long term competitive advantages by tying in customers but instead many loose and fragmented relationships will become the norm. An opposing view is given by Johnston and Vitale (1988), Johnston and Lawrence (1988) and Konsynski and McFarlan (1990). They argue that organisations will use IOSs for competitive advantage which can for example tie-in customers, lock out competitors and control access to privileged information. This suggests that organisations will choose to cooperate closely with important trading partners and develop IOSs for mutual benefits. The unit of analysis for competitive advantage becomes networks of organisations involved in the supply chain of specific product groupings rather than a single organisation's activities. Access to data will be privileged and competitors will develop competing systems. The resulting market structure is one of hierarchically arranged organisations integrated by IOSs - electronic hierarchies.

In the case of Motorola, the electronic markets theory is not supported and the evolution of electronic hierarchies seems the most probable direction. Motorola's cash management system is characterised by several themes; cooperation, trust and shared benefits with its customers, suppliers and Citibank. Close relationships based on manufacturing ties with suppliers are being augmented by a tight coupling of financial transactions which bring the cash flows in line with the product flows. There is no intention to open up the system to competitors or to involve a large number of competing banks. 
There are several possible explanations of the trend towards hierarchical structures instead of market ones which apply specifically to this case but also to business markets in general. A basic tenet of electronic markets theory is that it is possible to interchange suppliers quickly and easily. But business markets are characterised by stability, long term relationships and mutual adaptation to changing needs (Turnbull, 1986). In most cases it is neither possible or desirable to change suppliers in a short period of time. Instead limited organisational resources are being allocated to manage fewer relationships better and IOSs constitute a critical element of this strategic choice. The phenomenon of cooperative competitive strategies (Harrigan and Newman, 1990, Kanter, 1989) make it clear that there is great potential for exploiting IOSs to support and enable cooperative business relationships which depend on trust for their effective operation and their long term existence (Clemons and Row, 1992b, Hart and Estrin, 1991, Holland and Lockett, 1991).

The 'IT impact' theories considered make numerous and diverse predictions on what are likely to be the organisational and market forms of the future and proffer different explanations. But they do not address directly the long time scales and processes of organisational adaptation and learning which are an integral part of Motorola's strategy. The case work presented here and recent research (Venkatraman and Short, 1992, Meier and Sprague, 1991) suggest that evolution over a long period of time is an important aspect of large scale Information Systems. It appears that static end points will not occur but instead a process of continuous change incorporating innovation, cost reduction and quality improvement will be the norm over the lifetime of a system.

\section{Conclusions}

It has been shown that effective cash management can yield significant strategic benefits both in cost savings and better quality relationships with suppliers. In this paper an example of a currency netting model has been illustrated. It has been applied on an inter-organisational and global scale to reduce cash flows and foreign currency payments. The principle innovation implemented by Motorola and Citibank is to include Motorola's suppliers into the currency netting process. The coordination mechanisms for cash management between Motorola and its suppliers consists of two main processes. Firstly, Motorola's collection of payments data using an internal global e-mail system. Secondly, Citibank's capability to receive electronic payments data, process it and effect the relevant disbursements and communication with suppliers. The results have implications for banking, strategy implementation, business relationships and competition, and organisational change associated with the implementation of Information Systems.

The medium to long term implications for banks are that there will be a reduction in revenues from interest and a trend towards transaction based charging because of increased transparency of information throughout the cash supply chain. This is exemplified by the transmission of the value date of payments from Citibank direct to the supplier in addition to other value added information such as the remittance advice.

The payment system was not originally designed as a breakthrough system which would give Motorola a competitive advantage but as a means of reducing costs and then later to add value to first tier suppliers. However by gaining experience in currency netting between Motorola companies it was then in a position to extend the netting system to include suppliers. Citibank provided the necessary global expertise in disbursement which complemented Motorola's expertise in collection of payments data. Therefore two evolutionary strategies have been merged cooperatively to achieve synergistic benefits. This is an ongoing process and it is likely that further benefits will be achieved.

Competition in business markets takes place over a long period of time and it is not necessary to be able to switch suppliers for sourcing and payments overnight. The global EDI cash payment system described here signifies the trend towards increased financial integration between a manufacturing organisation and its suppliers. It therefore represents the development of an electronic hierarchy in which cash flows mirror product flows.

Motorola's treasury management function is continually changing and improving in order to reduce costs and improve the quality of its information to Motorola companies and their suppliers for better planning. Information Systems have had no pre-determined impact on the design of treasury management except to make it location independent. It can be run from anywhere in the world but the time zone differences make Europe more attractive. The capacity to change is limited by Motorola's ability to learn, adapt and influence trading partners. Technology is no longer a significant problem in implementation. Managing innovations, strategic alliances,organisational learning and change now present the critical issues. 


\section{References}

Benjamin R.I., D.W. De Long and M.S. Scott Morton (1988) "The Realities of Electronic Data Interchange: How Much Competitive Advantage?". Working Paper 1985-88. Management in the 1990s, Sloan School of Management Massachusetts Institute of Technology.

Cash J.I. and B.R. Konsynski (1985). " "IS Redraws Competitive Boundaries". Harvard Business Review, March-April, pp. 134142 .

Clemons E.K. and M.C. Row (1992a). "Rosenbluth International Alliance: Information Technology and the Global Virtual Corporation". In Nunamaker J.F. and R.H. Sprague (Eds.) Proceedings of the Hawaii International Conference on System Sciences, Vol. IV, pp. 678-686.

Clemons E.K. and M.C. Row (1992b). "Information Technology and Industrial Cooperation". In Nunamaker J.F. and R.H. Sprague (Eds.) Proceedings of the Hawaii International Conference on System Sciences, Vol. IV, pp. 644 653

Freeland J.R. and H.L. Ashby (1987). "An Exploratory Study Of Just-In-Time Purchasing In Japan And The United States". Presented at the Joint Meeting of The Institute of Management Sciences and Operations Research Society of America, New Orleans, May.

Hart P. and D. Estrin (1991). "Inter-Organization Networks, Computer Integration, and Shifts in Interdependence: The Case of the Semiconductor Industry". ACM Transactions on Information Systems, Vol. 9, No. 4, pp. 370-398.

Holland C.P. and A.G. Lockett (1991). "Forms of Association in Business Markets: The Impact of Inter-Organisational Information Systems". In Sharma (Ed.) "Selected Conference Proceedings of the 7th International Marketing and Purchasing Conference, Evolution, Structure, and Management, Uppsala, Sweden, 6-8 September, JAI Press, Greenwich, Connecticut, Volume 6, Advances in International Marketing Series.

Huber G.P. (1990). "A Theory of the Effects of Advanced Information Technologies on Organizational Design, Intelligence and Decision Making". Academy of Management Review, Vol. 15, No. 1, pp. 47-71.

Johnston R. and P.R. Lawrence (1988). "Beyond Vertical Integration - the Rise of the Value-Adding Partnership". Harvard Business Review, July-August, pp. 94-101.

Johnston H.R. and M.R. Vitale (1988). "Creating Competitive Advantage With Interorganizational Information Systems". MIS Quarterly, June, pp. 153-165.

Kanter R.M. (1989). "When Giants Learn to Dance". Unwin, London.
Keen P.G.W. (1990). "Telecommunications and Organizational Choice". In Fulk J. and C. Steinfield (Eds.) "Organisations and Communications Technology". Sage, London.

Keen P.G.W. (1991). "Shaping the Future". Harvard Business School Press.

Konsynski B.R. and F.W. McFarlan (1990). "Information Partnerships - Shared Data, Shared Scale". Harvard Business Review, September-October, pp. 114-120.

Malone T.W. and J.F. Rockart (1992). "Information Technology and the New Organization". In Nunamaker J.F. and R.H. Sprague (Eds.) Proceedings of the Hawaii International Conference on System Sciences, Vol. IV, pp. 636643.

Malone T.W., J. Yates and R.I. Benjamin (1987). "Electronic Markets and Electronic Hierarchies". Communications of the ACM, Vol. 30, No. 6, pp. 484-497.

Malone T.W., J. Yates and R.I. Benjamin (1989). "The Logic of Electronic Markets". Harvard Business Review, pp. 166170.

Manheim M. (1992). "Global Information Technology". International Information Systems, Vol. 1, No. 1, pp. 38-67.

Meier J. and R.H. Sprague (1991). "The evolution of interorganizational systems". Journal of Information Technology", 6, pp. 184-191.

Porter M.E. (1990). "The Competitive Advantage of Nations". Harvard Business Review, March-April.

Rockart J.F. and J.E. Short (1989). "IT in the 1990s: Managing Organizational Interdependence". Sloan Management Review, Winter, pp. 7-17.

Turnbull P.W. (1986). "Tri-Partite Interaction: The Role of Sales Subsidiaries in International Marketing". In Turnbull P.W. and S.J. Paliwoda (Eds.), "Research in International Marketing", Croom Helm, London, pp. 193-212.

Venkatraman N. and J.E. Short (1992). "Baxter Healthcare: Evolution from ASAP to ValueLink in the Hospital Supplies Marketplace". In Nunamaker J.F. and R.H. Sprague (Eds.) Proceedings of the Hawaii International Conference on System Sciences, Vol. IV, pp. 666-677.

Zuboff S. (1988). "In The Age Of The Smart Machine, The Future of Work And Power". Heinemann Professional Publishing, Oxford. 